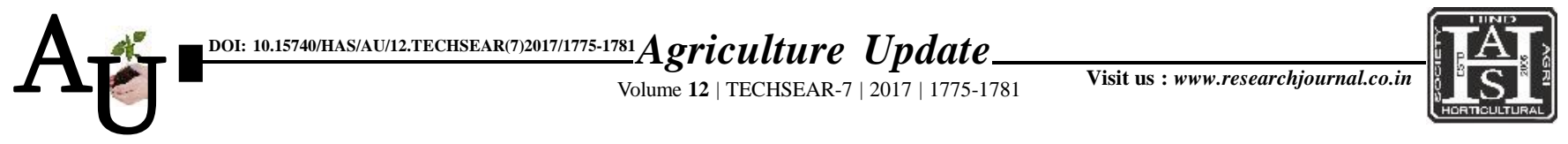

\title{
Research Article: Screening the populations of Mallada boninensis for cross resistance to newer molecules of insecticides
}

\author{
SRAVANTHI GUNTUPALLI, M. KALYANASUNDARAM AND R. RAJYA \\ LAKSHMI
}

Article Chronicle:

SUMMARY : Positive resistance ratios were recorded when the population of $M$. boninensis was Received : 19.07.2017;

Accepted :

03.08.2017

KEY WoRDS:

M. boninensis, Resistance, Cross resistance, Imidacloprid, Acetamiprid, Thiamethoxam, Buprofezin subjected to imidacloprid for four generations suggesting that the grubs showed resistance to the insecticide. Resistance ratio of 1.12 fold was recorded in the second generation and resistance ratio of 1.15 fold was recorded in the third generation. In the fourth generation grubs of M. boninensis when, treated with imidacloprid recorded resistance ratio of 1.25 fold in the fourth generation. Cross resistance ratio of 1.25 fold was recorded in the fifth generation to acetamiprid. Cross resistance ratio of 2.75 fold was recorded in the fifth generation to thiamethoxam. Cross resistance ratio of 2.09 fold was recorded in the fifth generation to buprofezin. Cross resistance ratio of 1.68 fold was recorded in the sixth generation to acetamiprid. Cross resistance ratio of 2.68 fold was recorded in the sixth generation to thiamethoxam. Cross resistance ratio of 1.93 fold was recorded in the sixth generation to buprofezin. Cross resistance ratio of 1.62 folds was recorded in the seventh generation to acetamiprid. Cross resistance ratio of 2.53 folds was recorded in the seventh generation to thiamethoxam and cross resistance ratio of 1.81 folds was recorded to buprofezin.

How to cite this article : Guntupalli, Sravanthi, Kalyanasundaram, M. and Lakshmi, R. Rajya (2017). Screening the populations of Mallada boninensis for cross resistance to newer molecules of insecticides. Agric. Update, 12(TECHSEAR-7) : 1775-1781; DOI: 10.15740/HAS/AU/12.TECHSEAR(7)2017/1775-1781.

Author for correspondence :

\section{SRAVANTHI}

GUNTUPALLI

Mango Research Station

(Dr.Y.R.H.U.), NUZVID

(A.P.) INDIA

Email :

sravanthiguntupalli@

gmail.com

See end of the article for

authors' affiliations 